\title{
Euterpe Oleracea Mart. Berries as Raw Material in Agro-Processes and Consumers Expectancies in French Guiana
}

\section{Robinson JC, Bereau D and Fahrasmane L*}

Université des Antilles et de la Guyane, UMR QUALITROP, P.O.Box 792 F-97 337, CAYENNE CEDEX, France

\begin{abstract}
Since many centuries, the Amerindian populations of Amazonia are consumers of a thick nutritive puree extracted from mature berries of Euterpe oleracea Mart. through manual rubbing of the fruits. Today, in French Guiana, urban populations are fond of this traditional puree, preferred of food products from various palm species. Marketed puree, nectar, has a short shelf life and is very often consumed after final preparation by consumers themselves, as drink diluted and sweetened, sometimes salted, or even associated with the flour of cassava in dish. The high content of anthocyanin in the pulp of wassaye and its antioxidant property has generated interest for this species outside of Amazonia. Beyond a demand continuous and constant supply of traditional nectar of wassaye, in Guiana, by all age brackets of consumers, there are demands for renewed products: stable, without hazard for the consumer health, sweetened, flavored. The development of better handling conditions and transformation of the harvest are needed, to produce raw materials and processed products of better quality, satisfying to quality expectations of today's consumers.
\end{abstract}

Keywords: Euterpe oleracea; Wassaye; Açai; French Guiana; Consumption; Processing

\section{Introduction}

Globally, palms family with 3000 species and 22 genera is an important botanical group, pantropically wide spread. Palms are the most versatile family of plants used by man, so, they are at the third place of sources of plant commodities, after cereals and vegetable. Uses and products are various and varied, of which some well known: edible oil (Elaeis guineensis), coconut oil and other products (Cocos nucifera), date (Phoenix dactilifera), masticatory (Areca catechu), carnauba wax, rattan furniture and baskets (Calamus), sap to prepare vinegar, palm wine, red resin (Daenomorops spp.), Recently arises an international interest for pulp of Euterpe oleracea berries, an ancestral staple food for indigenous Amerindians living on Guiana Highlands and in Amazonian forest.

Among the rich Amazonian biodiversity palm family is well represented with no less than 180 species. Wassaye is the vernacular call of Euterpe oleracea Mart. in French Guiana. It is called açai in Brazil. It is an economically significant palm species growing on seasonally flooded areas and along river courses. Wassaye fruit is a small berry of $1.2-1.6 \mathrm{~cm}$ in diameter. The fruit mesocarp is a thin layer of fibres and pulp covering the stone of an oval berry. The stone is about $80 \%$ of the volume of the fruit. Many centuries ago, this fruit was already consumed under the form of a thick nutritive puree, prepared through manual rubbing of mature berries macerated in lukewarm water, warmed at sunbeam, to facilitate the mesocarp removing form the stone. At 16th century, wassaye remained a staple food for Caboclos population issuing from Amerindian and European mixing. Towards 1750, wassaye consumption was widespread in the area of Amazon estuary. By the fact of rural exodus, it became a staple food in urban areas towards 1960, a trendy food towards 1970, and finally a manufactured product with international market growing at the 2000 edge [1]. Electric device diffusion, batederias, replacing manual pulp trituration was determining in the market expansion toward urban populations. Those last years, wassaye high content of anthocyanin and its antioxidant properties [2-5] have generated increasing interest for this fruit outside of South America. In vivo, antioxidant potential of wassaye has been shown by Mertens-Talcott et al. [6]. Many current processes, like cooling, deep-freezing, have been used to control and conserve aqueous extracts of wassaye to make possible overseas exportation. Wassaye extracts are exported from Brazil to NorthAmerica, Japan and Europe. Brazilian Amazonia is the main area of Wassaye collect with 200000-350000 tons of fresh fruit handled annually [7].

Today, handling, economy, and processing of wassaye are characterised by an informal feature. There is a non merchant domestic chain of production of wassaye extracts, rooted in the tradition, working at a familial or neighbourhood level, to feed members of a reduced circle. Traditional wassaye preparation is highly perishable with a short shelf life due to the proliferation and activity of bacterial flora of fruits surface $[8,9]$. It is sometime called wine or milk by reference respectively to its color or its nutritive properties, and often eaten mixed with cassava flour. Wassaye pulp is used as ingredient in functional foods, beverages, juice blends, yogurt, nectars, sorbet, smoothies, energy drink $[10,11]$.

The berries of wassaye are mostly harvested from wildness. The fruit harvest is qualified of "extractivism" [1]. Riparian inhabitants climb the palm stem that can reach a height of over $30 \mathrm{~m}$ and a diameter of 7 to $18 \mathrm{~cm}$, with archaic utensils of picking to catch generally one bunch by tree. A bunch can were 3 to $6 \mathrm{~kg}$ of fresh fruit [2]. Mature fruits are dark purple colored. The fruits are seconded from the rachillas of the bunch, put in flexible bags weighing full about $25 \mathrm{~kg}$ each. Then, the harvest

*Corresponding author: Fahrasmane L, INRA UMR 1270 QUALITROP, Domaine Duclos Prise d'eau F-97 170 PETIT-BOURG, France, Tel: +590 590255968 E-mail: Louis.Fahrasmane@antilles.inra.fr

Received December 21, 2012; Accepted March 05, 2013; Published March 15, 2013

Citation: Robinson JC, Bereau D, Fahrasmane L (2013) Euterpe Oleracea Mart. Berries as Raw Material in Agro-Processes and Consumers Expectancies in French Guiana. J Food Process Technol 4: 223. doi:10.4172/2157-7110.1000223

Copyright: (c) 2013 Robinson JC, et al. This is an open-access article distributed under the terms of the Creative Commons Attribution License, which permits unrestricted use, distribution, and reproduction in any medium, provided the original author and source are credited. 
is transported through hot and humid forest, on men shoulders and by boat, during many hours, before the pulp extraction. Some wassai are grown under different agroforestry systems. The fruit production is permanent, however with two seasons in Guiana: a high one during the rainy season between November and July, and a low one during the dry season between August and October. Wassaye berries are not eaten fresh, but by children who are fragmenting. Today, more or less thick beverages of diluted pulp of wassaye are considered as traditional and patrimonial of populations from Amazonas and Guianas highlands. Its high perishability had long been restricted its consumption and commercialization inside a perimeter very close to the pulp extraction place. In the merchant chain, from the tree to the consumer, there are tree main actor types working with few technologies:

- Harvesters who climb trees to collect bunch. Some of them have only this activity in the black as a source of incomes. Others are climbing to improve their incomes.

- Operators buying fruits from harvesters to produce a semi finished pulp extract marketed packaged in refrigerated plastic bag, with short shelf life. This pulp extract is prepared either according to traditional practices manually, or with a mechanical device: batederia.

- Retail vendors and food service operators using wassaye pulp as ingredient in elaborated food (ice cream, sherbet) or beverage [12].

Today, urban consumers' demands are for stable processed products with health properties preserved. Wassaye products market is flavored not only by local interest for socio-economical development based on traditional resources, but also by international consumer trends towards health, wellness and exotic flavors. Acceptance of food products wassaye-based is good and determined not only on their health properties but also on their sensory properties $[11,13,14]$.

The aim of this study conducted in French Guiana was to assess preferences of today's consumers for products wassaye-based, and begin exploration of routes for higher standards of products quality. The position of consumption of wassaye among food products from palm species was also assessed. The collected informations should provide criteria choices of treatment of the fruits and their processing to elaborate new products from wassaye, that meet expectations of modern consumers. French Guiana is today an European enclave, in tropical America, of $84200 \mathrm{~km}^{2}$ for 221178 inhabitants [15], highly cosmopolitan (more than 130 nationalities represented), distributed on $5 \%$ of the territory, more than an half living in urban areas. The lifestyle developed being rather Westerner, while integrating aboriginal foods and practices.

\section{Material and Methods}

Qualitative information on consumer preferences and method of utilisation of wassaye fruit was collected by consumer and processing surveys.

\section{Consumer surveys}

A radio broadcast of large audience on Guiana territory (France Television) with a call to listener to react by telephone on the forms of traditional palm trees products consumption.

A survey was conducted to know preferences and consumption modes. Consumption survey was conducted by one interviewer. He directly administrated the questionnaires to two hundreds individual respondents, one hundred women and one hundred men of any ages and from any communities. Structured closed-ended questionnaires were used, composed of 18 questions, to assess: relative consumption of the tree main palm nectars, volumes consumed weekly, forms of consumption, firsts buying criteria, consumers' expectations in respect of properties of new products, were assessed. The importance of consumption modes (percentage) in relation to the gender and the age of the consumer were calculated. The sampling method used was by quotas. The sub-populations selected to achieve our quotas have been the gender.

\section{Processing survey}

Its goal was to identify cultural, traditional and food operators practices in wassaye treatments. It was conducted among a sample of 5 food operators. The method was an open discussion with note taking.

\section{Statistical analysis}

The statistical analysis of the results was performed with the software Statgraphics Centurion XV. The statistical law which has been used is the binomial distribution.

$P$ values $<0.05$ were regard as significant. Error was calculated with the formula $1.96 \sqrt{p(1-p) / n}$, where $\mathrm{P}$ was the percentage of response and $\mathrm{n}$ the sample size.

\section{Results}

\section{Radio station call to consumers}

The informal feature of wassaye collect and uses make impossible availability of quantifiable data about quantities handled in French Guiana. History, listening of people and observation are ways for appreciate the place and potential of wassaye. Listeners reaction after a radio broadcast call have shown that every year, at the Christian feasts period of Passover and Pentecost, there is an increase of the demand of palm raw extracts higher than the supply capacity. The short shelf life of the products, even refrigerated, made very difficult to stock up traditional extract at household level. Out of those periods of Christian feast, the consumption volume is permanent and constant. In urban areas it is feed essentially by people from communities that traditionally consume daily palm nectars: Brazilian and Bushinengue.

\section{Consumer of palm nectars and surveyed population demographics}

200 consumers of palm food products were surveyed. The surveyed population's characteristics are detailed according to table 1 . The quota of the respondents by gender, and in every group of age, was $50 \%$. Respectively only $2 \%$ of the respondents was more than 75 years old, $5 \%$ was in the $60-74$ age group, $21 \%$ was in the $39-59$ age group, $30 \%$ was in the 20-39 age group and $42 \%$ was in the less than 20 years old. This distribution by age is closed with the distribution profile of French Guiana population.

Proportion of the population of Guiana consumers of palm food products prepared from tree major species of the local biodiversity was assessed. A large majority of two hundreds surveyed individuals, i.e. $78 \pm 6 \%$, declared consume at least one product from the three main palms used in diet (wassaye, comou or patawa).

\section{Place of wassaye}

Wassaye was the more consumed among the tree main palm sources 
Citation: Robinson JC, Bereau D, Fahrasmane L (2013) Euterpe Oleracea Mart. Berries as Raw Material in Agro-Processes and Consumers Expectancies in French Guiana. J Food Process Technol 4: 223. doi:10.4172/2157-7110.1000223

Page 3 of 5

\begin{tabular}{|c|c|}
\hline \multicolumn{2}{|c|}{ Features of questioned persons } \\
\hline Woman & $50 \%$ \\
\hline Man & $50 \%$ \\
\hline Less than 20 years old & $42 \%$ \\
\hline 20 to 39 years old & $30 \%$ \\
\hline 39 to 59 years old & $21 \%$ \\
\hline 60 to 74 years old & $5 \%$ \\
\hline Over 75 years old & $2 \%$ \\
\hline
\end{tabular}

Table 1: Characteristics of a panel of 200 consumers surveyed.

of food, prepared as nectar or puree, in Guiana. $87 \pm 5 \%$, of surveyed consumers of palm food used it, and $47 \%$ and $36 \%$ respectively was user of nectar from comou (Oenocarpus bacaba) and patawa (Oenocarpus bataua) (Figure 1). Wassaye was a major traditional food in Guiana, while its economy, particularly the collect activity, is still in the informal economic sector. View the important place of Wassaye, it was selected like model for our study of palm tree products consumption.

\section{Modes and volume of consumption of wassaye}

Food products prepared from wassaye are consumed in different manners in Guiana (Figure 2). The surveys showed that its consumption as nectar, a regularly diluted pulp, is the fact of more than $95 \%$ of the consumers of wassaye surveyed. This nectar is sweetened by $80 \%$ of the consumers. The wassaye pulp extract is also used as meal, in an association with cassava flour (Manihot esculenta), by $85 \%$ of the palm products users.

Two forms of finished wassaye nectar are purchased: "grosso", a thick pulp extract having a high rate of dry matter, or "fino" a lighter pulp extract with a low rate of dry matter. Consumer preference for those two products was about equally distributed (Figure 2).

Survey about volume of wassaye food product consumed showed that more than $90 \%$ of consumers used at least one liter by week. Generally, the wassaye nectar is sold in refrigerated plastic bags containing one liter. Those consuming at least two liters were more than $60 \%$ (Figure 3).

\section{Purchase criteria}

Consumers had quality criteria for wassaye food products. It was essentially the taste for $82 \%$ of them, and far behind the texture: grosso or fino (Figure 4). The product color is very dark, usually a deterioration color, low indicative about the product quality. It is surely why the color is not highly significant as purchase criteria.

Modes of consumption and consumer's gender A survey about the modes of consumption of wassaye, according to the consumer gender, showed that there were no significant differences between genders, but for the consumption of a lightened product in fat there was a higher percentage of female favorable than of male, and the difference between these percentage was significantly different (Figure 5). Lipids are more than $50 \%$ of dry matter in wassaye [16]. Wassaye food products contain no far of $50 \%$ of lipids on dry matter and it is possible to reduce their content in lipid by centrifugation.

\section{Mode of consumption and consumer age}

Here, we have excluded results coming from surveyed individuals more than 59 years old, because they were few. Results in figure 6 showed no significant differences between the groups of age. Age is not a discriminating factor in the mode of consumption (Figure 6). It appears a good transmission of appreciation and knowledge of wassaye products from generation to generation.

\section{Processing survey}

We conversed with fifteen operators. They worked in accordance

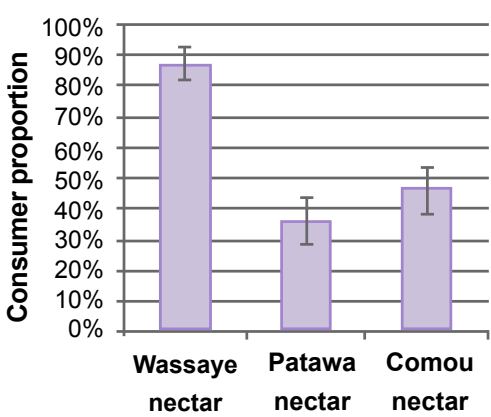

Figure 1: Consumer proportion taking palm tree nectars.

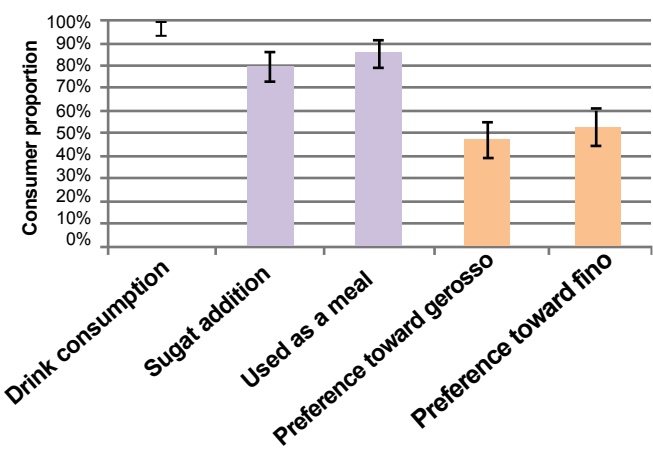

Figure 2: Mode of consumption of Wassaye.

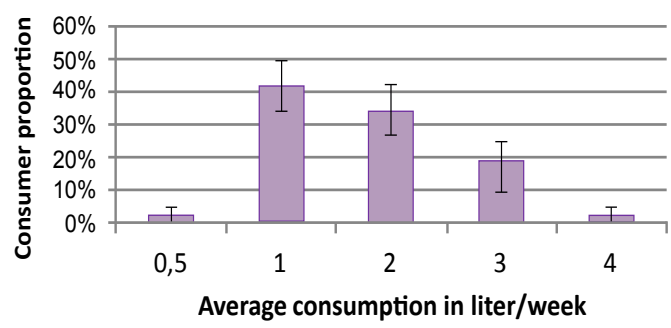

Figure 3: Volume and frequency of consumption.

\section{First purchase criteria}

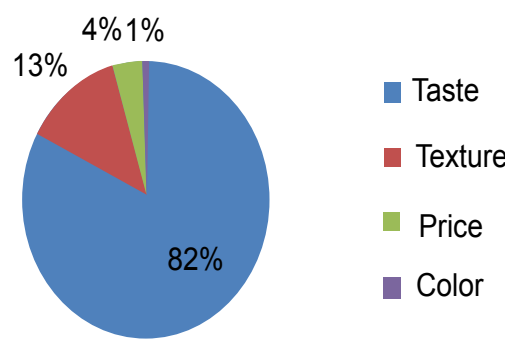

Figure 4: Purchase criteria distribution 
with figure 7. Operations are essentially manual. Only the pulp extraction is mechanized. There were no disinfection and/or heat treatment neither of the raw material nor the processed pulp. To increase the shelf life of the processed products, to warrant food safety to the consumer, heat treatments, pasteurization at 80 and $90^{\circ} \mathrm{C}$, could be applied $[8,17]$ with significant contamination reduction. Boiling was not recommended because it influences negatively sensorial properties [17]. Non heating sterilizing treatments are desirable, like tangential microfiltration, to preserve thermolabile properties.

\section{Discussion}

Development of knowledge about traditional Amazonian societies and their uses of the biodiversity from their natural environment, place today some plant species, like Euterpe oleracea Mart. at the crossing of traditional food practices with food health expectancies of modern consumers. To make it fruitful, acceptance issues are raised. Wassaye could be a model of palm products gaining popularity in urban Guiana and worldwide.

The traditional product, a thick brown nutritive beverage highly perishable, is appreciated even by young consumers, because among the $87 \%$ of consumers of wassaye nectar surveyed (Figure 1), the bulk $(42 \%+30 \%)$ (Table 1$)$ is made of less than 39 years old. However, more than $80 \%$ of the consumers add sweeteners to their consumption,

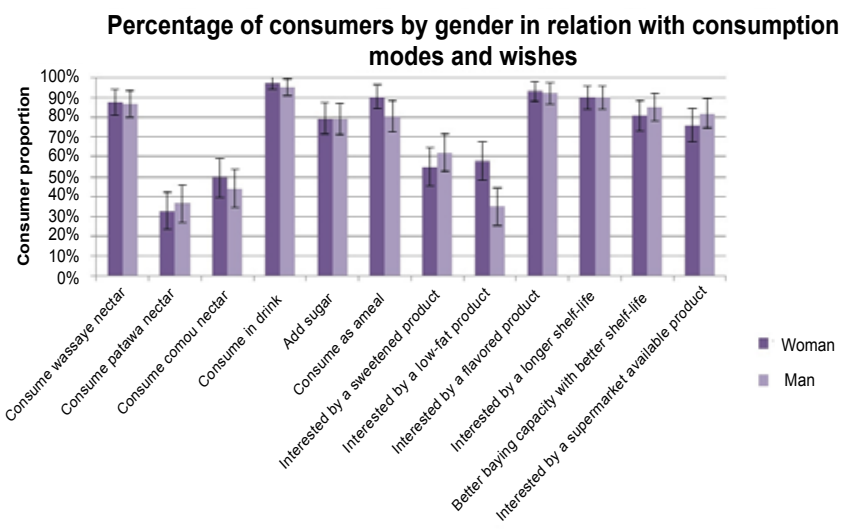

Figure 5: Percentage of consumers by gender in relation with consumption modes and wishes.

Percentage of consumer in relation with mode and consumer's age

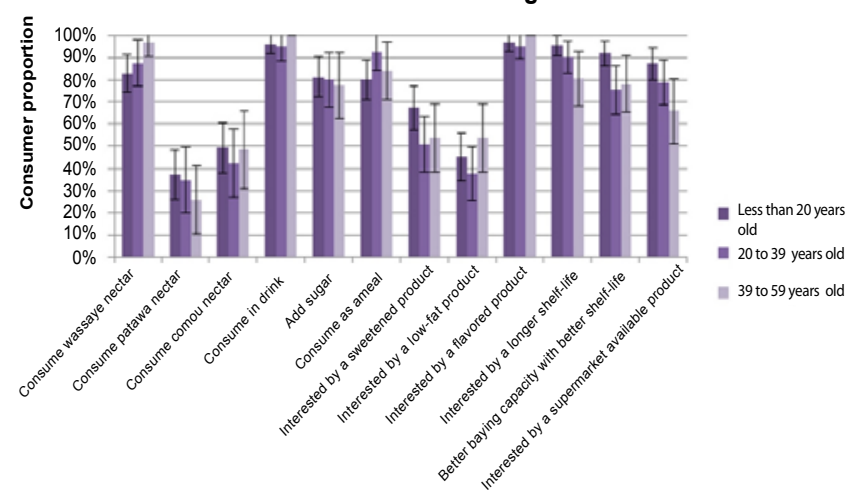

Figure 6: Percentage of consumer in relation with mode and consumer's age.

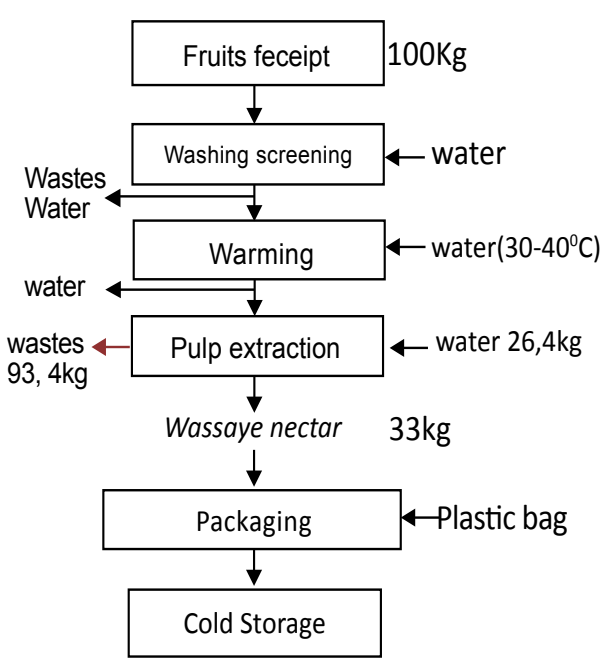

Figure 7: Diagram of wassaye nectar processing.

and the same percentage express interest for flavored product. The sweetening practice and flavoring expectancy reveal formulation possibilities for new products. Interests expressed for products with better shelf life, available in mass market structures, rather by less than 20 years old surveyed individuals (Figure 6), represents a general desire for stabilized products, like those currently available on mass market shelves. The food products prepared from wassaye fruits, in Guiana, are obtained on the basis of ancestral manners, giving a high perishable aqueous extract sold only in the informal economic sector. It is determining to develop technological routes to elaborate products matching modern network distribution requirements: labeled, packaged, long shelf-life, lightened by fat for women (Figure 5), with sensory profiles of current food and drinks, while preserving health claim properties Palm fruits are harvested and handled in precarious conditions in the forest: under warm tropical temperatures, packaged in mass in bags without sanitation. Delays between harvest and processing are rather long and not controlled. The low acidity of Wassaye bays with a $\mathrm{pH}$ between 5,2 and 5,3 [8] and friction forces occurring in the $25 \mathrm{~kg}$ bag of transportation put the fruit pulp in contact with the microbial flora present on the fruit epicarp. In the post-harvest treatments of the fruit there are not sanitation operations of the harvest (Bleaching, washing), and the lukewarm water bringing to facilitate the pulp extraction could generate favorable condition for bacterial activity.

Some modern technologies have been tested on pulp and products quality. Freeze-dried pulp keeps good antioxidant capacity [18]. Powder produced with some carrier agents preserved antioxidant activity [19]. High pressure treatment is efficient against microorganisms [20]. Innovative treatments protecting biologic properties are to involve in new products formulation. Microfiltration of centrifuged açai product, which is sterilizing, is also efficient protecting antioxidant activity, according to Cruz et al. [21]. The production of a puree showing satisfying microbial quality, have to be studied. This puree could be a raw material for elaboration of culinary products, functional foods, and personal hygiene products. Beyond a demand continuous and constant supply for the raw traditional nectar wassai-based, in Guiana, there are expectancies for renewed products: stable, without hazard for the consumer health, with sweet and aromatic properties in mouth. Development of improved handling conditions of the collected fruits 
Citation: Robinson JC, Bereau D, Fahrasmane L (2013) Euterpe Oleracea Mart. Berries as Raw Material in Agro-Processes and Consumers Expectancies in French Guiana. J Food Process Technol 4: 223. doi:10.4172/2157-7110.1000223

must be elaborated to limit and control the activity of the natural microflora on the fruit surface, to get raw material and products of better quality. It is not easy, because the bulk of the fruits are extracted from the wild. There is a work of formulation of new products to undertake [11], to afford today's consumers' expectancies. We are now experimenting for routes for products corresponding to higher quality standards, in order to respond to today's consumers' expectancies.

\section{Acknowledgement}

Our acknowledgements to Michel PHAN for his contribution to this study during his training for an engineer degree Supagro Montpellier; and to Samue FAURE for his assistance for the figures.

\section{References}

1. Brondizio ES, Safar CAM, Siquiera AD (2002) The urban market of Açaí fruit (Euterpe oleracea Mart.) and rural land use change: Ethnographic insights into the role of price and land tenure constraining agricultural choices in the Amazon estuary. Urban Ecosystems 6: 67-97.

2. Del Pozo-Insfran D, Brenes CH, Talcott ST (2004) Phytochemical composition and pigment stability of Açai (Euterpe oleracea Mart.). J Agric Food Chem 52 1539-1545.

3. Pacheco-palencia LA, Hawken P, Talcott ST (2007) Juice matrix composition and ascorbic acid fortification effects on the phytochemical, antioxidant and pigment stability of açai (Euterpe oleracea Mart.). Food Chem 105: 28-35.

4. Canuto GAB, Xavier AAO, Neves LC, Benassi MT (2010) Caracterizacao fisico-quimica de polpas de frutos da Amazônia e sua correlacao com atividade anti-radical livre. Revista Brasileira de Fruticultura 32: 119-125.

5. Mulabagal V, Keller WJ, Calderón Al (2012) Quantitative analysis of anthocyanins in Euterpe oleracea (açaí) dietary supplement raw materials and capsules by Q-TOF liquid chromatography/mass spectrometry. Pharm Biol 50: 1289-1296.

6. Mertens-Talcott SU, Rios J, Jilma-Stohlawetz P, Pacheco-Palencia LA Meibohm B, et al. (2008) Pharmacokinetics of anthocyanins and antioxidant effects after the consumption of anthocyanin-rich acai juice and pulp (Euterpe oleracea Mart.) in human healthy volunteers. J Agric Food Chem 56: 77967802

7. Sabbe S, Verbeke W, Deliza R, Matta V, Van Damme P (2009) Effect of a health claim and personal characteristics on consumer acceptance of fruit juices with different concentrations of açaí (Euterpe oleracea Mart.). Appetite 53: 84-92

8. Sousa MADC, Yuyama LKO, Aguiar JPL, Pantoja L (2006) Acai juice (Euterpe oleracea Mart.): microbiological evaluation thermal treatment and shelf life. Acta Amazonica 36: 497-502.

9. Pessoa JDC, Da Silva E Silva PV (2007) Effect of temperature and storage on açaí (Euterpe oleracea) fruit water uptake: simulation of fruit transportation and pre-processing. Fruits 62: 295- 302

10. Coïsson JD, Travaglia F, Piana G, Capasso M, Arlorio M (2005) Euterpe Oleracea juice as a functional pigment for yogurt. Food Res Int 38: 893-897.

11. Menezes E, Deliza R, Chan HL, Guinard JX (2011) Preferences and attitudes towards açaí-based products among North American consumers. Food Res Int 44: 1997-2008

12. Plotkin MJ, Balick MJ (1984) Medicinal uses of South American palms. J Ethnopharmacol 10: 157-179.

13. Sabbe S, Verbeke W, Van Damme P (2009) Analysing the market environment for açaí (Euterpe oleracea Mart.) juices in Europe. Fruits 64: 273-284.

14. Vidigal MCTR, Minim VPR, Carvalho NB, Milagres MP, Gonçalves ACA (2011) Effect of a health claim on consumer acceptance of exotic Brazilian fruit juices: Açaí (Euterpe oleracea Mart.), Camu-camu (Myrciaria dubia), Cajá (Spondias lutea L.) and Umbu (Spondias tuberosa Arruda). Food Res Int 44: 1988-1996.

15. INSEE (2011) Recensement de la population 2008. Populations légales des communes en vi gueur au $1 \mathrm{er}$ janvier.

16. Caroline T (1999) Etude de la productivité et de la composition du jus de fruits de quatorze types génétiques de la variété Noire du palmier açaí (Euterpe oleracea Mart.) de l'estuaire amazonien.

17. Oliveira PAAC, Silva IG, Souza ML, Furtado CM, Silva RF (2009) In natura açaí beverage: quality, pasteurization and acidification. Ciência e Tecnologia de Alimentos 31: 502-507.

18. Schauss AG, Wu X, Prior RL, Ou B, Huang D, et al. (2006) Antioxidant capacity and other bioactivities of the freeze-dried Amazonian palm berry, Euterpe oleraceae mart. (acai). J Agric Food Chem 54: 8604-8610.

19. Tonon RV, Brabet C, Hubinger MD (2010) Anthocyanin stability and antioxidan activity of spray-dried açai (Euterpe oleracea Mart.) juice produced with different carrier agents. Food Res Int 43: 907-914

20. Laboissière LHES, Deliza R, Barros-Marcellini AM, Rosenthal A, Camargo LMAQ, et al. (2007) Effects of high hydrostatic pressure (HHP) on sensory characteristics of yellow passion fruit juice. Innovative Food Science \& Emerging Technology 8: 469-477.

21. Cruz APG, Mattietto RA, Taxi CMAD, Cabral LMC, Donangelo CM, Matta VM (2011) Effect of microfiltration on bioactive components and antioxidant activity of açai (Euterpe oleracea Mart.). Desalination and Water Treatment 27: 97-102. 